Revista lus et Praxis, Año 24, No 3, 2018, pp. 453 - 476

ISSN 0717 - 2877

Universidad de Talca - Facultad de Ciencias Jurídicas y Sociales

El surgimiento del jus sanguini como criterio general de asignación de la nacionalidad:

Algunos antecedentes que explican su aparición

Carlos Amunátegui Perelló

Trabajo recibido el 18 de abril de 2017 y aprobado el 22 de agosto de 2018

\title{
El surgimiento del jus sanguini como criterio general de asignación de la nacionalidad: Algunos antecedentes que explican su aparición
}

\author{
THE EMERGENCE OF JUS SANGUINI AS A GENERAL CRITERION FOR ASSIGNING \\ CITIZENSHIP. SOME CONSIDERATIONS ABOUT ITS APPARITION
}

\section{Carlos Amunátegui Perelló*}

\section{REsUMEN}

Hasta comienzos del siglo XIX, el jus soli era el modo usual para adquirir la nacionalidad en los diversos estados de Europa. Sus orígenes, en último término generados durante la Edad Media por los glosadores y comentaristas, se encontraban interconectados con la noción de soberanía. Su eficiencia era tal que la existencia de personas sin estado en los regímenes políticos de Europa era casi imposible. Con la dictación del Code Napoléon se introdujo el jus sanguini como criterio principal para atribuir nacionalidad. Su establecimiento se enfrentó a toda la tradición jurídica Occidental e incluso a los deseos personales de Napoléon. Esto obliga a interrogarse acerca de los motivos que tuvo la comisión codificadora para imponer un criterio tan inusual en dicha época. Creemos que en la base de tal medida se encuentran las primeras obras que establecieron los fundamentos de la pseudo ciencia conocida como racismo científico.

\section{ABSTRACT}

Until the beginning of the 19th century, jus soli was the standard means to acquire citizenship in most European states. It's origins- ultimately developed by the glossators of the middle age- were interconnected with the notion of sovereignty. It's level of efficiency was such, that there was virtually no stateless people in Europe. With the enactment of the Code Napoléon the jus sanguini was introduced as the main device to attribute citizenship. This innovation was introduced against the standards of Western legal tradition and even against Napoléon's own wishes. This odd fact begs for an explanation regarding the motifs the Commission had to enact such an unusual criterion at the time. We think that at the very base of it, we can find the first works of a pseudo-science which came to be known as scientific racism.

$$
\begin{gathered}
\text { PALABRas CLAVE } \\
\text { Jus soli, jus sanguinis, raza, nación } \\
\text { Key words } \\
\text { Jus soli, jus sanguinis, race, nation }
\end{gathered}
$$

\footnotetext{
* Licenciado en Ciencias Jurídicas Pontificia Universidad Católica de Chile. Doctor en Derecho, Universitat Pompeu Fabra. Profesor de Derecho Romano, Pontificia Universidad Católica de Chile. Correo electrónico: camunate@uc.cl.
} 


\section{Introducción}

Durante los últimos años la adquisición de nacionalidad se ha convertido en uno de los temas más debatidos en el ámbito social y político ligado a las migraciones. En efecto, el tema no sólo ha sido parte del debate presidencial de Estados Unidos, sino también de Francia, mientras que conmovedores vídeos circulan por Internet de niños a quienes se informa que, a pesar de haber nacido en Dinamarca, no tienen la nacionalidad danesa. Este artículo intenta contribuir al debate académico estableciendo una historia simplificada de las reglas de adquisición de nacionalidad en las sociedades occidentales, esto es, de los Ilamados jus soli y jus sanguine, a fin de aportar información relevante acerca de su formación y de las ideas que Ilevaron a su adopción. Este ejercicio histórico-comparado intentará contribuir al debate otorgando un análisis detallado de los argumentos que sustentan la adopción de estos sistemas de atribución de nacionalidad.

\section{Con nombres latinos}

Las expresiones jus soli y jus sanguine son los terminos usuales con los que se designa a dos diferentes sistemas de adquisición de nacionalidad, entorno a los cuales la mayor parte de las sociedades occidentales tiende a diseñar sus instituciones de atribución de nacionalidad. Sin embargo, como suele ocurrir, no hay ninguna institución romana detrás de estos dos latinazgos. De hecho, las reglas de atribución de ciudadanía en el mundo romano parecen bastante diversas a las nuestras. En el viejo mundo romano, la ciudadanía podía adquirirse por nacimiento, por liberación o mediante una concesión especial de la ciudad. Al respecto, sólo nos interesan las reglas relativas a la adquisición de la ciudadanía por nacimiento. Se establecía que el hijo matrimonial obtenía la ciudadanía de su padre, cualquiera que fuese ésta ${ }^{1}$, mientras que el hijo no matrimonial la obtenía de su madre ${ }^{2}$. Las razones subyacentes a tal atribución están íntimamente relacionadas con las concepciones romanas acerca de los lazos de familia. El vínculo entre los miembros de un grupo familiar se sustentaba en el hecho de haber estado todos sus miembros bajo la patria potestas del mismo pater (usualmente el hombre más anciano del grupo), quien tenía un poder absoluto sobre sus miembros, lo que incluso podía manifestarse en

\footnotetext{
1 D.1.5.19 Celsus libro 29 digestorum. Cum legitimae nuptiae factae sint, patrem liberi sequuntur: volgo quaesitus matrem sequitur.

2 D.1.5.24 Ulpianus libro 27 ad Sabinum Lex naturae haec est, ut qui nascitur sine legitimo matrimonio matrem sequatur, nisi lex specialis aliud inducit.
} 
la facultad que detentaba de matarlos ${ }^{3}$. Estos eran los adgnati, que también eran conocidos como familia propio iure, por cuanto era este tipo de relación la que creaba consecuencias jurídicas ${ }^{4}$. Las relaciones de parentesco fuera de este estrecho marco, usualmente carecían de consecuencias jurídicas, por lo que eran estimadas naturales, esto es, comunes a seres humanos y animales ${ }^{5}$ y opuestas a las relaciones jurídicas.

En cualquier caso, este criterio para atribuir la ciudadanía cambiará sustancialmente a comienzos del siglo III d.C. En el año 212 el emperador Antonino Caracalla otorgó la cuidadanía romana a todos los habitantes del imperio ${ }^{6}$. Aunque las causas y consecuencias de esta concesión masiva siguen siendo controvertidas, para nuestros propósitos la consecuencia fundamental de este acto es la alteración total del criterio para asignar ciudadanía durante la Antigüedad tardía, que pasa de relaciones de poder en la familia a la residencia. Fue la residencia dentro del Imperio el factor determinante para otorgar la ciudadanía, cuando el Imperio Romano tardío se transformaba lentamente en un Estado

\footnotetext{
3 La peculiar naturaleza de las relaciones de familia en el Derecho romano ha estado bajo fortísimo debate durante más de un siglo. De hecho, parece haber dos explicaciones para su particular carácter. Por una parte, las relaciones de familia han sido concebidas como instituciones con un carácter primariamente político. Cada familia sería una unidad política regida por un individuo que la comanda de manera soberana, el pater familias (Véase: Bonfante (1963), pp. 7 y ss. y De Martino (1953), pp. 25 y ss.). Otra explicación apuntaría a la familia como una suerte de unidad económica. En la Roma republicana no habría existido una palabra fija para describir la propiedad, por lo que las relaciones de poder que parecen constituir el núcleo del concepto de familia en Roma imitarían los poderes que el hombre tiene sobre los bienes materiales para usarlos y disponer de ellos. En esta línea véase: ArANGIORuiz (1914), seguido por Voci (1953), p. 101; KASER (1960) y Pugliese (1985), pp. 11 y ss.

${ }^{4}$ D.50.6.195.2 Ulpianus libro 46 ad edictum. Familiae appellatio refertur et ad corporis cuiusdam significationem, quod aut iure proprio ipsorum aut communi universae cognationis continetur. Iure proprio familiam dicimus plures personas, quae sunt sub unius potestate aut natura aut iure subiectae, ut puta patrem familias, matrem familias, filium familias, filiam familias quique deinceps vicem eorum sequuntur, ut puta nepotes et neptes et deinceps. Pater autem familias appellatur, qui in domo dominium habet, recteque hoc nomine appellatur, quamvis filium non habeat: non enim solam personam eius, sed et ius demonstramus: denique et pupillum patrem familias appellamus. Et cum pater familias moritur, quotquot capita ei subiecta fuerint, singulas familias incipiunt habere: singuli enim patrum familiarum nomen subeunt. Idemque eveniet et in eo qui emancipatus est: nam et hic sui iuris effectus propriam familiam habet. Communi iure familiam dicimus omnium adgnatorum: nam etsi patre familias mortuo singuli singulas familias habent, tamen omnes, qui sub unius potestate fuerunt, recte eiusdem familiae appellabuntur, qui ex eadem domo et gente proditi sunt.

${ }^{5}$ D.1.1.1.3 Ulpianus libro primo institutionum. Ius naturale est, quod natura omnia animalia docuit: nam ius istud non humani generis proprium, sed omnium animalium, quae in terra, quae in mari nascuntur, avium quoque commune est. Hinc descendit maris atque feminae coniunctio, quam nos matrimonium appellamus, hinc liberorum procreatio, hinc educatio: videmus etenim cetera quoque animalia, feras etiam istius iuris peritia censeri.
}

${ }^{6}$ Dig1.5.17 Ulpianus libro 22 ad edictum In orbe Romano qui sunt ex constitutione imperatoris Antonini cives Romani effecti sunt. 
territorial. La cuidadanía romana significó que sólo había un derecho para el Imperio, en contraste con los diversos derechos personales de la era anterior, de la misma forma que había sólo un gobernante y, luego de la adopción del cristianismo, un solo Dios.

No obstante, el marco jurídico de la ciudadanía entró en conflicto con las realidades económicas del Imperio tardío. Durante la República tardía y el Principado, Roma se había convertido en una economía de mercado ${ }^{7}$. En tal contexto, la movilidad geográfica era una de las características fundamentales que el dominio romano sobre el Mediterráneo trajo a la Antigüedad. Cicerón, definiendo el espíritu del cosmopolitanismo antiguo dice: patria est ubicumque est bene (Cic., Tusc. Disp., 5.108), la patria está donde quiera que uno esté bien. De hecho, el mito que hace que Rómulo funde Roma como un asilo que daba la bienvenida a quien quiera que migrase a ella, puede haber sido diseñado con la expresa intención de legitimizar la existencia de un cuerpo ciudadano basado no en el nacimiento, sino en el deseo de convertirse en romano ${ }^{8}$.

En cualquier caso, las necesidades productivas de la economía eran satisfechas sólo parcialmente con el mercado de trabajo ${ }^{9}$, mientras que la presión por movilizar mano de obra gatilló una masiva transferencia de población heterónoma basada en la esclavitud, donde millones de prisioneros de guerra fueron vendidos en el mercado como mano de obra.

No obstante, durante el Imperio tardío, estas presiones cedieron, según la economía de mercado en Roma se comprimía y reducía. Las consecuencias

\footnotetext{
7 El papel de los mercados en la economía romana ha estado bajo debate desde la década del '70, cuando Finley publicó su estudio clásico Ancient Economy. Ahí propuso un modelo económico para la Antigüedad en donde los mercados jugaban un papel menor y secundario, solamente de cierta relevancia en algunas áreas urbanas mayores del Imperio. Esta perspectiva rápidamente fue apoyada por distintos académicos que propusieron un bajo nivel de monetarización para la economía romana y una escasa importancia de los mercados en la fijación de los precios (en la materia, véanse: FinLEY (1999), pp. 95-122; Crawford (1970), pp. 40-48; MeikLE (2012), pp. 233-250). No obstante, durante los últimos quince años la postura opuesta ha tomado fuerza, estableciendo la existencia de niveles de monetarización más profundos en todo el Imperio y destacando el funcionamiento de una economía de mercado propiamente tal para la República tardía y el Principado, véase: GreENE (1990), pp. 45-66 y Von ReDen (2012), pp. 266-285. Acerca del dinero crediticio en la economía romana: HARRIS (2011), pp. I.2557-2936. Para una argumentación favorable a la existencia de verdaderos mercados financieros en Roma, véase: Temin (2012), pp. 157-191. Acerca del rol de los impuestos y su distribución en este proceso, véase: Hopkins (2002), pp. 190-232. Para el debate en su conjunto, véase: BANG (1997), pp. 1-21.

${ }^{8}$ MORLey (2006), p. I.5167.

${ }^{9}$ El papel del trabajo libre en la República tardía ha sido objeto de bastante debate en el último tiempo. Algunos académicos sugieren la existencia de un verdadero mercado de trabajo para la época. Véase: HaRRIS (2011), pp. I.546-578 y KenOE (2012), pp. 114-131. La aproximación más extrema es de Temin (2013), pp. 114-138.
} 
catastróficas de la crisis del siglo III d.C. y la extendida demonetarización del Imperio llevaron ${ }^{10}$ a un movimiento contrario a fin de fijar la mano de obra. La fuerza de trabajo esclava se hizo rara y fue paulatinamente reemplazada por coloni en vastas áreas del Imperio ${ }^{11}$, quienes eran ciudadanos nominalmente libres, pero adscritos a la tierra por vínculos que en la Edad Media darían origen al feudalismo.

Mientras las presiones económicas demandaban el control de movimientos dentro del imperio, el marco jurídico dio a todos los habitantes del mismo la ciudadanía romana, por lo que nuevos mecanismos jurídicos debían ser diseñados a fin de domar su movilidad y limitar su movimiento. En este contexto es que un nuevo conjunto de normativas y regulaciones se produjo a fin de fijar las fuerzas productivas del Imperio. Se creó una suerte de legislación laboral, que apuntaba a limitar la movilidad del trabajador y adscribirlo a su lugar de origen. Bajo Constantino el Grande, los trabajadores agrícolas no podían dejar sus trabajos hasta que la cosecha estuviese terminada ${ }^{12}$, mientras que, un poco más tarde, Valentiniano y Valente les prohibieron totalmente dejar sus tierras de origen ${ }^{13}$. A los gobernadores imperiales se les encargó la tarea de retornarlos a sus lugares de nacimiento, en caso que fuesen aprehendidos en otro ${ }^{14}$, estableciendo una prohibición formal de no incluirlos en ningún censo ciudadano ni otorgarles derecho a residir ${ }^{15}$.

En este contexto es que la cuestión del origen de las personas se hizo, nuevamente, muy relevante. En el Imperio tardío, era el origen de una persona el que entregaba el derecho a establecerse o residir, por lo que la residencia adquirió un estatus en algún grado equivalente a la ciudadanía ${ }^{16}$. Ahora bien, el origen de una persona se establecía con su nacimiento, de acuerdo al origen de su padre y, de ahí, el lugar donde podía vivir. Una serie de decisiones imperiales

\footnotetext{
10 Lo CASCIO (2000), pp. 307-326.

11 Acerca de sus aspectos económicos, véase: Marcone (1997), pp. 151-174. En sus aspectos jurídicos, véase: SiRks (1999), pp. 419-430 y SiRks (2008), pp. 120-143. También SaNTILLI (1999), pp. 275-292.

12 C.11.48.1.

13 C.11.48.3.

${ }^{14}$ C.11.48.6.

15 C.11.48.11.

16 Siglos más tarde, el comentarista medieval Baldo, señaló que la residencia era una forma (cuasi) de ciudadanía: Nam ratione domicilii est effectus sub illa lege: quam quasi civis est. BALdo Ubaldi (1577a), p. 8 (16).
} 
clarificaron este punto ${ }^{17}$. En el nuevo Imperio Cristiano nacido de las cenizas del siglo III d.C., aunque la ciudadanía romana era universal, había una suerte de semiciudadanía que dependía del nacimiento, que, en último término otorgaba el derecho a residir en un lugar determinado del Imperio.

Luego de la descomposición y colapso de la mitad Occidental del Imperio, las reglas jurídicas comunes se disolvieron en las turbulentas aguas de la Alta Edad Media y sólo emergieron una vez que la tormenta de traída por las invasiones y el masivo despoblamiento cedieran para crear un nuevo mundo, uno que eventualmente adoptaría las reglas jurídicas anteriores.

Cuando finalmente las reglas jurídicas romanas fueron redescubiertas a comienzos del siglo XII, los glosadores rápidamente extrajeron conocimiento jurídico de los antiguos textos. Los diferentes pasajes que versaban sobre ciudadanía y residencia en el Corpus luris fueron anotados y comentados a fin de darle un sentido sincrónico a lo que era esencialmente un grupo de diversas reglas diacrónicas. Por un lado, estaba la concesión de ciudadanía romana a todos los habitantes del Imperio, mientras que por otro, estaba este conjunto de reglas que distinguía entre las personas según su origen -origo-. En este contexto, el glosador Azón comenta que una persona puede ser miembro de una ciudad (munícipes, de munus, carga, esto es, alguien que comparte las cargas), por nacimiento, liberación o por opción, siendo esta relación con una ciudad la verdadera ciudadanía ${ }^{18}$.

Aunque el viejo Imperio Romano había explotado en diversos reinos hacía cientos de años, durante la Edad Media aún se conservaba un sentido de unidad que involucraba las dimensiones política, jurídica y religiosa. Había un Derecho -el recién redescubierto Derecho romano, llamado ius commune-, un emperador -el emperador del Sacro Imperio Romano Germánico- y una Iglesia. Durante la Baja Edad Media, una nueva concepción de la relación entre el soberano y el territorio emergió, una donde cada rey tendría el poder jurídico en exclusiva en cada reino, más allá de las ambiciones de los emperadores alemanes, que fueron desprovistos de sus aspiraciones universales y considerados solamente como reyes de las tierras que efectivamente controlasen. En este contexto, Baldo de Ubaldi, un comentarista del siglo XIV, señaló explícitamente que el Emperador no podía gobernar a aquellos que no eran

\footnotetext{
17 Esto fue decidido en una serie de rescriptos que comienzan con el propio emperador Antonino Caracalla y llegan hasta Constantino (C.10.39.1; C.10.39.3; C.10.39.4; C.10.39.5). El principal problema parece ser el estatuto de los estudiantes, los cuales deambulan por diversas ciudades del Imperio.

18 Azzonis (1596), p. 1097: Municipes aut nativitas facit, aut manumissio aut optio. Et dicuntur propie municipes, quasi muneris participes in civitatis sic recepti, ut munera nobiscum facerent... tunc municipes dicamus cuiuscunque civitatis, ut puta cives Campanos, Puteolanos...
} 
directamente sus propios súbditos ${ }^{19}$, no pudiendo imponer reglas jurídicas a quienes no estuviesen bajo su dependencia directa ${ }^{20}$. En cuanto a la pregunta relativa sobre quiénes eran los súbditos del emperador, ésta fue respondida desde una nueva perspectiva, aunque siempre interpretando los viejos textos. Baldo estableció una diferencia entre ciudadanos de origen y otros que podían adquirir la ciudadanía por otros medios ${ }^{21}$. Aquellos que habían adquirido la ciudadanía por nacimiento, eran considerados ciudadanos naturales (cives naturales). En otro texto, señala expresamente que un ciudadano de origen es aquel que ha nacido en esa ciudad ${ }^{22}$, así, si alguno ha nacido en Florencia, es florentino de origen. Desde este momento, los nuevos Estados que emergen en Europa Occidental durante los siglos XV y XVI adoptarán sistemáticamente esta regla, que unos siglos más tarde será denominada jus soli: todo hombre nacido en un territorio será ciudadano del lugar en donde nazca.

En este contexto, ya en el siglo XIII el Reino de Castilla había establecido que el derecho de la tierra era obligatorio incluso para los extranjeros ${ }^{23}$. Más aún, establecía expresamente que una persona era natural de la tierra donde había nacido ${ }^{24}$, el que era considerado su origen natural. Cuando España se convirtió en un Estado moderno luego del matrimonio entre Isabel de Castilla y Fernando de Aragón, las reglas de las Siete Partidas acerca de la ciudadanía se mantuvieron en vigencia, por lo que el jus soli se convirtió en el derecho propio de España, lo que se mantuvo en vigencia hasta comienzos del siglo XIX ${ }^{25}$.

19 Imperator non imponit leges nisi subditis. BALDO (1577b), p. 5.

20 Imperator nec de iure, nec de facto possit imponere legem non subditis. BALDo (1577b), p. 6.

21 BALDO (1577c), p. 33.

22 Baldo (1577a), p. 278. In loco originis, et in colatus, cogitur quis subire onera... Nota ex eo, quod dicit, Biblium ex origine, quod ítem est, quod dicere Florentinum, et natum de Florentia, quod declara, ut plene dixi in l.j. ad munic.... De incolis, et ubi quis domicilium habere videtur. Et de his, qui studiorum causa in alia civitate degunt.

23 "Todos aquellos que son del señorío del fazedor de las leyes, sobre las cosas que pone, son tenudos de las odedecer e guardar, e juzgarse por ellas... E esso mismo dezimos de los otros que fueren de otro señorio, que fiziessen el pleyto, o postura, o yerro en la tierra dose juzgasse por las leyes: ca maguer sean de otro lugar non pueden ser escusados de estar a mandamiento dellas". (Siete Partidas, Partida 1, Ley 15).

${ }^{24}$ Siete Partidas, Partida 2, Título 20, Ley 1: "Por mayor tovieron los sabios antiguos aquella naturaleza que los omes han con la tierra por nascer en ella".

${ }^{25}$ La Novísima Recopilación de 1805 impone una nueva regla. Para convertirse en clérigo debía nacerse dentro de los territorios españoles de padres españoles (I. 7, t. 14, I. 1 de la Novísima Recopilación). No obstante, a comienzos del siglo XIX, esta regla fue interpretada de manera que implicase que sólo aquellos nacidos dentro del territorio español de padres españoles eran naturales de España. Véase: Bello (1886), p. 107; Asso y Manuel (1806), p. 35; Tapia García (1828), p. 7 y Escriche (1875), p. 255. 
En Francia la situación era similar. Durante el período en que Francia se configura como un Estado moderno, en 1315, mediante un decreto real de Luis $X$, se estableció que por Derecho natural, quien quiera que hubiese nacido en Francia era francés ${ }^{26}$, en concordancia con la doctrina de Baldo ${ }^{27}$. En 1515 esto fue confirmado por una sentencia del Parlamento de París ${ }^{28}$. Durante el siglo XVIII, la doctrina ya era antigua y fue sintetizada por Pothier en los siguientes términos ${ }^{29}$ : "Los ciudadanos, los verdaderos y naturales franceses, siguiendo la definición de Bacquet, son aquéllos nacidos dentro de los límites de los dominios franceses".

Inglaterra, con el bien conocido caso de Calvin v. Smith, en $1608^{30}$ adoptó la misma regla, estableciendo que quien quiera que hubiese nacido bajo los dominios del rey era inglés. Si esta regla fue el resultado de la recepción del ius commune o un desarrollo paralelo del Derecho inglés, permanece como un aspecto a estudiar. En cualquier caso, Blackstone sintetiza la situación en los siguientes términos ${ }^{31}$ : "La primera y más obvia división de las personas es entre extranjeros y súbditos naturales. Los súbditos naturales son aquéllos que han nacido dentro de los dominios de la corona de Inglaterra, esto es, bajo la lealtad (ligeance), o como es generalmente conocida, soberanía (allegiance) del rey; mientras que extranjeros son los que han nacido fuera de ella".

Para el siglo XVIII la regla común entre los estados europeos era que una persona pertenecía al reino en el cual había nacido. La interpretación de Baldo del viejo Derecho romano y los requerimientos políticos de los nacientes Estados modernos fueron las dos fuerzas que impulsaron este fenómeno. No obstante, había casos en que la nacionalidad de los padres podía ser tomada en cuenta a fin de otorgar la nacionalidad a sus descendientes cuando estos no habían nacido en el territorio de la corona. Así, por ejemplo, los parlamentos franceses

\footnotetext{
26 Dalloz y Dalloz (1840), p. 199

27 Este decreto real también estableció la liberación de todos los esclavos en Francia, por lo cual tuvo una importancia enorme.

28 Berdah (2006), p. 142.

29 Pothier (1846), p. 17: Les citoyens, les vrais et naturels Français, suivant la définition de Bacquet, sont ceux qui sont nés dans l'etendue de la domination française...

30 Robert Calvin nació en Escocia después de que ésta cayese bajo el dominio inglés. Cuando murió, su herencia incluía tieras en Inglaterra. Si se lo consideraba inglés, entonces dichas tieras podían pasar a sus herederos, pero, puesto que no había nacido en Inglaterra, la cuestión terminó siendo litigada. Finalmente, se decidió que quienquiera que hubiese nacido en territorios de la corona, sería considerado súbdito del rey y, por tanto, inglés. Véase: Price (2013), pp. 73-145; Dumbraya (2014), p. I.537.

31 Blackstone (1765), p. 354.
} 
la concedían judicialmente ya desde el siglo XVI, aunque esto era más bien excepcional ${ }^{32}$.

Contrariamente a la creencia de la academia actual ${ }^{33}$, durante el Antiguo Régimen, la ciudadanía era uno de los tres estados que una persona podía tener, mientras que el estado de familia y de libertad eran los otros dos restantes ${ }^{34}$. La ciudadanía no podía variarse ${ }^{35}$ y era una de las fuentes fundamentales de derechos y obligaciones para las personas desde su nacimiento.

El sistema funcionaba bien. Los estados más grandes de Europa Moderna lo seguían y, a su alero, la existencia de apátridas era casi imposible. Aunque las fronteras de la Europa Moderna cambiaron de tanto en tanto, la ausencia de ciudadanía no parece haber sido un problema, por cuanto las reglas del jus soli eran tan claras y simples que, incluso, se llegó a generalizar la creencia de que la determinación de la ciudadanía a través del lugar de nacimiento era una cuestión de derecho natural y, de ahí la consideración de súbditos o ciudadanos naturales que se dio a quienes la adquirían por este medio. Todo esto cambiará cuando la Revolución Francesa caiga como una tormenta sobre la Europa Moderna.

\section{Revolución y cambio}

La Revolución Francesa fue el evento jurídico más espectacular de los dos últimos siglos. Todas las principales características del mundo jurídico actual provienen de una u otra forma de ella. A primera vista, el jus soli no se oponía a los ideales revolucionarios. En efecto, su tono universal hizo que el jus soli fuese acogido por los intelectuales revolucionarios, aunque se le agregaron otros principios a fin de ampliar su ámbito.

\footnotetext{
32 WeIL (2008), p. I.147; Berdah (2006), p. 142.

33 Por ejemplo, Weil señala que "From this point on [the enactment of the French Civil Code] nationality became a right attached to the person: like the family name, it was transmitted by fatherhood; it was attributed at birth; it was no longer lost if its holder established resindency abroad". WEIL (2008), p. I.100.

${ }^{34}$ En la mayor parte de los libros jurídicos básicos, que tras el siglo XVI solían seguir el modelo de las Instituciones de Justiniano, la materia se encontraba tratada en lo relativo al estado de las personas -usualmente en el libro primero-, justo después del status de libertad y antes del estado de familia. Esto proviene directamente de la influencia romana, como en las Institutas de Gayo -y por tanto en las de Justiniano-, quien habla de ciudadanía al finalizar sus explicaciones acerca del estatus de los esclavos liberados. Al respecto véase la muy influyente obra del siglo XVII, VINNIUs (1755), p. 44, la cual, como texto básico para la enseñanza de alumnos de primer año, fue utilizada por parte de todos los estudiantes europeos e incluso americanos.

${ }^{35}$ C.10.39.4 Imperatores Diocletianus, Maximianus. Origine propria neminem posse voluntate sua eximi manifestum est. ${ }^{*}$ DIOCL. ET MAXIM. AA. SECUNDO. ${ }^{*}<$ A XXX $>$.
} 
En los primeros años de la Revolución, al haber nacido en suelo francés, se agregaron el nacer de un padre francés o el simple hecho de establecer residencia en Francia para otorgar la ciudadanía francesa ${ }^{36}$. Incluso, a algunos de los más relevantes héroes del imaginario revolucionario se les otorgó la nacionalidad francesa, no obstante el hecho que ellos no hubiesen vivido jamás en Francia ni tuviesen ninguna conexión aparente con el país, como fue el caso de Thomas Payne, George Washington y Jeremy Bentham, entre $\operatorname{otros}^{37}$. Entre los criterios para otorgar la ciudadanía francesa, el más importante, al menos para la opinión pública, era todavía el lugar de nacimiento. En los textos que apuntaban a la educación política de la población francesa, la definición de un ciudadano francés era bastante simple: a la pregunta de quiénes son ciudadanos franceses, la respuesta era, quien quiera que hubiese nacido en Francia ${ }^{38}$.

Aunque las constituciones que posteriormente se irían dictando restringirían la ciudadanía francesa, el jus soli permaneció como la característica fundamental del sistema hasta la promulgación del Code Napoléon de $1804^{39}$. En cualquier caso, ya durante la discusión de la Constitución de 1799, aquella escrita inmediatamente después del golpe que puso a Napoléon en el poder, una nueva tendencia emergió, que reclamaba la ciudadanía francesa exclusivamente para aquellos que hubiesen nacido de padres franceses, dejando como apátridas a una segmento creciente de la población. Esto llegará a ser conocido más tarde como jus sanguinis ${ }^{40}$. Aunque esta tendencia fue derrotada a comienzos de la era napoleónica, más adelante, durante la redacción del Código Civil francés, volverá a alzarse nuevamente y, eventualmente, se

\footnotetext{
36 De hecho, la Constitución de 1791 reconoció el estatus de ciudadanos de aquellos que eran descendientes de las personas expulsadas de Francia por razones religiosas. El artículo señala:

Article 2. - Sont citoyens français:

- Ceux qui sont nés en France d'un père français;

- Ceux qui, nés en France d'un père étranger, ont fixé leur résidence dans le Royaume;

- Ceux qui, nés en pays étranger d’un père français, sont venus s'établir en France et ont prêté le serment civique;

- Enfin ceux qui, nés en pays étranger, et descendant, à quelque degré que ce soit, d'un Français ou d'une Française expatriés pour cause de religion, viennent demeurer en France et prêtent le serment civique. Véase al respecto: Brubaker (1993), p. 6; Weil (2008), p. I.189.

37 Berdah (2006), p. 143; WeIL (2008), p. I.200.

38 D. Quels sont ceux qu'on appellé en France citoyens

R. Tout homme né et domicilié en France àgé de 21 ans accomplis, tout étranger àgé de 21 ans accomplis qui domicilié en France depuis d'une année...

ANÓNIMO (II año de la República), p. 5.

${ }^{39}$ Véanse las constituciones de 1793, artículo 2; 1795, artículo 8 y 1799, artículo 2.

40 El término viene de mediados del siglo XIX, del trabajo de la escuela Exegética.
} 
impondrá en contra de la tradición jurídica francesa, de las generosas tendencias iniciales de la Revolución e, incluso, en contra de los deseos del propio Napoléon.

A comienzos de la era napoleónica, el golpe que llevó al joven general al poder (9 de noviembre de 1799) fue apoyado por muchas figuras intelectuales de la Revolución, entre quienes se encontraba Emmanuel-Joseph Sieyès. En este contexto, se redactó una nueva constitución a fin de dar legitimidad al gobierno de Napoléon. No obstante, emergieron conflictos entre Napoléon y Sieyès respecto de este documento jurídico. Sieyès deseaba una constitución balanceada, que no entregase el poder absoluto a ningún hombre o institución, mientras que Napoléon tenía otra cosa en mente. Finalmente, la lucha fue perdida por Sieyès, quien debió retirar su proposición y dejar el camino abierto para la nueva constitución napoleónica. Entre las proposiciones de Sieyès estaba el otorgar la calidad de francés -durante esta época el término nacionalidad todavía no estaba en uso ${ }^{41}$ - a aquellos que hubiesen nacido, sea en Francia, sea en el extranjero, de un padre francés ${ }^{42}$. En cualquier caso, esta proposición fue desechada por el mismo Napoléon, merced al apoyo de Pierre Daunou $^{43}$, quien propugnaba la noción tradicional del jus soli. Finalmente, el artículo $2^{\circ}$ de la Constitución de 1799 señalaba ${ }^{44}$ que:

"Todo hombre nacido y residente en Francia, quien, habiendo cumplido los veintiún años, se inscriba en el registro civil de su comuna, y que haya permanecido desde entonces un año completo en el territorio de la República, es ciudadano francés".

Si se observa atentamente, este artículo no define la nacionalidad, sino que la ciudadanía. En dicha época, la ciudadanía era entendida como el derecho a participar activamente en los asuntos públicos, lo que suponía que el ciudadano tenía también la nacionalidad. Se interpretó el artículo en el sentido de que otorgaría la nacionalidad a aquellos que naciesen en Francia, mientras que extendería la ciudadanía a los que cumpliesen los demás requisitos: ser hombre, tener al menos veintún años, haber realizado la inscripción y haber residido en Francia al menos un año ${ }^{45}$.

\footnotetext{
41 WeIL (2008), p. I.100.

${ }^{42}$ WeIL (2008), p. I.299.

43 WeIL (2008), p. I.304.

${ }^{44}$ Article 2. Tout homme né et résidant en France qui, âgé de vingt et un ans accomplis, s'est fait inscrire sur le registre civique de son arrondissement communal, et qui a demeuré depuis pendant un an sur le territoire de la République, est citoyen français.

45 Ngaire Heuer (2007), p. 129; Weil (2008), p. I.282.
} 
En cualquier caso, durante la discusión del Código Civil francés, la idea volvió a emerger. Se nombró una comisión para redactar el Código en 1800, integrada por François Denis Tronchet, a la sazón presidente de la Corte de Casación, Jean-Étienne-Marie Portalis y Félix Julien Jean Bigot de Préameneu. El trabajo de esta commission fue discutido por el Consejo de Estado, donde el propio Napoléon participó, junto con Théophil Berlier, Antoine Jacques Claude Joseph (conde de) Boulay de la Meurthe y Jean Jacques regis de Cambacérès, quien ya había preparado varias propuestas de Código Civil y era, por entonces, segundo cónsul junto a Napoléon. Fue durante la sesión del 14 de termidor del año 9 de la Revolución $\left(1^{\circ} \text { de agosto de } 1801\right)^{46}$, que el Consejo de Estado discutió el artículo relevante $\left(7^{\circ}\right)$, relativo a la nacionalidad ${ }^{47}$. Tronchet propuso que sólo los hijos de franceses fuesen franceses, sea que naciesen dentro o fuera del país. Esta proposición fue inmediatamente rechazada por el Consejo de Estado. Cambacérès apuntó que un niño expósito quedaría como apátrida. Boulay señaló que la Constitución ya otorgaba la calidad de francés a aquellos nacidos en Francia, incluso de padres extranjeros. Napoléon propuso que se reemplazara el artículo por otro que simplemente rezara que ${ }^{48}$ : "Cualquier individuo nacido en Francia es francés". Tronchet defendió su principio señalando que imponer la nacionalidad francesa a alguien cuyos padres no eran franceses simplemente porque había nacido en territorio francés seria injusto y que eso sería contrario a los viejos principios del Derecho civil. A eso respondió Napoléon que un niño nacido en Francia tendría una crianza francesa y que eso lo haría francés. La posición de Tronchet fue rápidamente rechazada y el Consejo de Estado adoptó la propuesta de Napoléon. En este sentido, la proposición original del Consejo de Estado terminó conteniendo tanto el jus soli como el jus sanguinis para otorgar la nacionalidad francesa al nacimiento.

En cualquier caso, el proyecto de Código Civil debía también ser aprobado por el Tribunado, una asamblea que, amén de otros deberes, debía supervisar el proceso legislativo. Puesto que estaba presidida por Pierre Daunau, el mismo hombre que ya había ayudado a Napoléon a aprobar la Constitución de 1799, el proceso debía marchar sin mayores contratiempos. En cualquier caso, esto no fue así. Hubo una fuerte oposición en el Tribunado a muchas de las proposiciones contenidas en el proyecto. La oposición al jus soli fue encabezada por Joseph-Jerome (conde de) Siméon, quien hizo un informe al

\footnotetext{
${ }^{46}$ Weil da una fecha distinta: el 25 de Julio de 1801, pero el 14 de Termidor es la fecha que figura en los archivos del Consejo de Estado. Véase: WEIL (2008), p. I.304.

47 Consell D'État (1841), pp. 12 y ss.

48 "Tout individu né en France, est Français" COnSElL D'ÉtAT (1841), p. 12.
} 
respecto ${ }^{49}$. Aparentemente, el argumento más importante esgrimido fue que no existía reciprocidad a la regla y, por tanto, el hijo de un inglés sería tenido por francés, pudiendo éste llevar sus riquezas de vuelta a Inglaterra, si así lo decidiese $^{50}$. De acuerdo a su visión, el jus soli sería simplemente un efecto colateral del feudalismo ${ }^{51}$. Finalmente, la regla fue rechazada por la comisión que volvió a la propuesta de Tronchet. El texto fue presentado nuevamente al Tribunado y aprobado con el jus sanguinis como el único criterio para atribuir la nacionalidad francesa al nacer el 18 de marzo de $1803^{52}$.

No resulta sencillo interpretar los hecho transcurridos en los poco años que van desde 1799 a 1803, cuando el principio emergió y se convirtió en la característica dominante del régimen jurídico francés. Hasta entonces, el jus soli había sido adoptado universalmente por todos los estados europeos y tenía la aprobación general de los más importantes pensadores políticos de su tiempo ${ }^{53}$. Estos no solían dedicarle demasiada atención al problema, mientras que los juristas usualmente describían la interpretación de Baldo en la materia como la regla estandarizada ${ }^{54}$. Se ha sido propuesto que Tronchet, como abogado, habría adoptado el principio del jus sanguinis producto de su labor forense, toda vez que en numerosas ocasiones había alegado este principio a favor de sus clientes. También se ha señalado que su respeto por el Derecho romano habría sido central en su idea de establecer este principio como exclusivo $^{55}$. En cualquier caso, su preferencia por el jus sanguinis no tendría por qué haber excluido al jus soli, especialmente en contra de una tradición que se había hecho consustancial a la estructura misma del estado moderno.

\footnotetext{
${ }^{49}$ Los capítulos del Código Civil fueron presentados al Tribunado el 11 de Frimario y una comisión se formó a fin de analizar la materia al día siguiente. Esta fue integrada por Boisjolin, Boissy, Caillemer, Chabot, Siméon, Thiessé y Roujoux. Un informe de la comisión se presentó el 25 de ese mismo mes por Siméon, mientras que la discusión continuó el 5 de Nivoso, con argumento de Malherbe a favor del jus soli.

50 Véase: Coin-Deliste (1865), p. 225.

51 WeIL (2008), p. I.395. El informe completo está disponible en MAVIDAL y LAURENT (1864), pp. 165 y ss.

52 WeIL (2008), p. I.415.

53 La única excepción que hemos podido encontrar es Pufendorf, quien creía en una teoría política contractualista donde sólo los descendientes de los primeros ciudadanos -aquellos que habían aceptado el contrato social para constituir la ciudad-, serían propiamente llamados ciudadanos. PufEndorf (1682=1927), p. 126.

54 Debemos señalar que, en cualquier caso, algunos académicos, como Cuyacio, señalaron que la interpretación de Baldo era inexacta y que la ciudadanía romana se transmitía al nacer considerando la ciudadanía del padre.

55 WeIL (2008), p. I.350.
} 
En cualquier caso, existen algunas pistas que podrían llevarnos por un camino distinto para determinar las razones que estarían detrás de la construcción de las reglas de atribución de nacionalidad durante la codificación francesa. En la misma época en que los ensordecedores cañones napoleónicos campeaban por Europa, una nueva ciencia emergía silenciosamente, susurrando oscuras palabras a los intelectuales del iluminismo: el Ilamado "racismo científico" nacía, y con él un conjunto de ideas que ya estaban presentes en el imaginario colectivo europeo tomaron un nuevo y triste derrotero.

\section{Una ciencia oscura}

El racismo no es nuevo para la mentalidad occidental. Muchas clases de prejuicios han sido construidos en la larga historia europea, los cuales eventualmente se expandieron alrededor del mundo con la expansión de la civilización europea durante los siglos XVI y XVII. Algunos de los más ilustres pensadores de la llustración mantenían opiniones que implicaban una brutal perspectiva racial. Una de las primeras teorías raciales en Francia fue postulada por Henri (conde) de Boulainvilliers en su influyente Histroire de l'Ancien Gouverment de la France (1727). Su tesis central consiste en que la nación francesa se compone de dos razas diversas, una germánica que desciende de los Francos y que forma el núcleo de la nobleza, y otra galo-romana, que fue sometida por aquella, la cual es predominante entre los comunes o tercer estado. Para él, la nación francesa es una suerte de unión fundada por el rey entre los francos (o en su nomenclatura, simplemente los franceses) y los galos ${ }^{56}$. La posición dominante de la aristocracia se fundamentaría en la conquista de los Galos por parte de los Francos (o simplemente franceses). La mezcla de sangres, que habría comenzado con la coronación de Hugo Capeto, habría hecho peligrar la estabilidad de la nación. Sus concepciones se hicieron populares entre la nobleza y se hicieron comunes durante el siglo XVIII, tanto que incluso las encontramos en la Encylopédie de Diderot ${ }^{57}$.

Durante el siglo XVIII, muchas nuevas disciplinas científicas se enraizaron en Europa. Antes, la mayor parte de los conocimientos sistemáticos, sean relativos a la naturaleza o al hombre, eran considerados, de una forma o de otra, parte de la filosofía. En cualquier caso, desde los rutilantes éxitos científicos de la Edad Moderna europea en física y cartografía, un nuevo conjunto de disciplinas apareció, las que se distinguían por mantener sus propios métodos

\footnotetext{
56 De BoulainVilliers (1727), pp. 32-36.

57 De hecho, en la voz française puede encontrarse un rápido resumen de la teoría de Boulainvilliers, que expresamente distingue entre las dos razas que conformarían la nación francesa.
} 
y objetos de estudio, los que eran predefinidos rigurosamente de acuerdo a los estándares modernos. Estas disciplinas fueron arrancadas de la filosofía como pétalos a una flor, para ser de ahora en adelante, denominadas ciencias. Esta es la época de Lavoisier, el fundador de la química moderna, de Adam Smith, el fundador de la economía moderna y también de Carl Linnaeus, el fundador de la taxonomía científica.

Linnaeus era un académico de reconocido prestigio por haber realizado una contribución mayúscula a la biología al clasificar todas las especies naturales en géneros. Su obra mayor, el Systema naturae per tria regna, publicada en 1735, estaba dividida en tres partes, las que correspondían a los tres reinos naturales; uno para los minerales, otro para los vegetales y un tercero para los animales. Él trató el reino animal mediante la clasificación de todos los tipos de animales conocidos, donde existía un género para los mamíferos (mamalia), el cual se dividía en diversas ramas, una de las cuales estaba ocupada por los primates, entre quienes se encontraba el hombre-homo ${ }^{58}$. Los hombres, a su vez, estaban clasificados en seis tipos diversos: Ferus (salvaje), Americanus, Europaeus, Asiaticus, Afer y Monstruosus ${ }^{59}$. A cada tipo humano unió un conjunto de características, como el color de su piel y otras particularidades físicas y morales. No necesitamos entrar en las especificidades de dicha distinción, aunque, por ejemplo; podríamos decir que el tipo afer era negro, flemático, torpe y regido por el capricho; el americano era descrito como colérico, oscuro de piel, de risa fácil y estaba regido por la costumbre; mientras que el europeaus era blanco, muy inteligente y estaba regido por los ritos.

Aunque los prejuicios y las características contenidos en estos tipos humanos no son nuevos, es importante destacar que ésta es la primera vez que una descripción de las razas humanas está contenida en una obra científica que pone al hombre en un contexto natural como una especie entre muchas otras, siguiendo estándares objetivos (geografía y color de la piel). El racismo, de pronto, se hizo parte de una nueva ciencia que desgraciadamente estaba siendo desarrollada por una de las mentes más brillantes de la Ilustración europea. Las consecuencias serían devastadores en el futuro.

La oscura antorcha de esta nueva ciencia fue tomada por uno de los más influyentes pensadores científicos de la Ilustración, Georges-Luis Leclerc, conde de Buffon (1707-1788). Uno de los miembros más jóvenes que jamás hayan sido aceptados en la Academia francesa y nombrado director del Jardin des

\footnotetext{
58 LiNNAEUS (1757), p. 18.

59 Linnaeus (1757), pp. 20-22. De acuerdo a Bethencourt, en la primera edición de 1735, ferus y monstrosus no estaban incluidos, como tampoco las descripciones que sucedían a los términos. Vid: BetHenCOURT (2013), p. I.6121.
} 
Plantes. Buffon tenía una impecable reputación científica. Escribió una impresionante historia natural en treinta y seis volúmenes, que lo convirtió en una de las figuras científicas más prominentes de su tiempo. Su trabajo influenció a la Encyclopaedie de Diderot y tuvo un efecto masivo en la Ilustración europea. Uno de sus trabajos más controvertidos fue el relativo al hombre y las razas humanas, la Histoire Naturelle de l'Homme et de la Femme, donde, siguiendo a Linnaeus, clasificó a los seres humanos de acuerdo a las razas, definidas por color de piel, forma corporal general y carácter ${ }^{60}$. Su trabajo es una vasta descripción de diversos tipos humanos en los distintos continentes, a veces llegando a la descripción pormenorizada de cada país. Las características raciales eran, de acuerdo a Buffon, consecuencias del clima, la alimentación y las costumbres ${ }^{61}$. El mestizaje era uno de los más importantes eventos que podía alterar una raza, sea para mejorarla o para degenerarla ${ }^{62}$, creando nuevas naciones, como fue el caso de los tártaros que serían una mezcla de chinos y rusos. La mezcla y la degeneración racial eran materias fuertemente debatidas durante la ilustración. Incluso Kant, bajo la influencia de Buffon ${ }^{63}$, escribió una serie de artículos acerca de la raza, donde señala que cuando las razas se mezclan producen mestizos, mientras que cuando los miembros de una misma raza se reproducen, heredan a sus descendientes al azar las características de cada uno de los padres ${ }^{64}$. Él se opone explícitamente a la mezcla de razas e incluso la teme ${ }^{65}$.

Montesquieu también cayó bajo la influencia de esta ciencia oscura. Él propuso que los diversos climas afectaban la constitución física y moral de los habitantes de una región ${ }^{66}$, provocando que los pueblos de los climas fríos fuesen más valientes y fuertes que aquellos de climas cálidos. De acuerdo a su análisis, la gente de la India, por ejemplo, sería "naturalmente gente pusilánime" ${ }^{67}$. En este sentido, un buen legislador debiese tener en cuenta estas características si desea que su legislación sea exitosa ${ }^{68}$.

\footnotetext{
${ }^{60}$ LeCLerC (1834), p. 173.

${ }^{61}$ Para una descripción general: BethenCOuRT (2013), p. I.6153.

${ }^{62}$ LeCLERC (1834), p. 175.

63 MikKelsen (2013), p. I.266.

${ }^{64}$ Por ejemplo, en su ensayo de 1788, Über den Gebrauch teleologischer Principien in der Philosophie, define la raza como una línea común de ascendencia. En el mismo, expresamente trata el problema del mestizaje. Para un estudio reciente, véase: MiKKELSEN (2013), p. I.4306.

65 MikKelsen (2013), p. I.328.

${ }^{66}$ Montesquieu (1772), pp. 283-286.

67 Montesquieu (1772), pp. 283-286.

${ }_{68}$ Montesquieu (1772), p. 379.
} 
Pero, aunque el clima intelectual favoreciese el tomar en cuenta consideraciones racistas a la hora de legislar, debiésemos determinar la presencia de estas ideas en los proponentes del jus sanguinis como el único medio para adscribirse en la nación a fin de establecer si es que existió una motivación racista detrás de la institución. Eso es complejo, toda vez que muchas de las ideas que motivan a la legislación no son expuestas abiertamente, sino que propuestas indirectamente o se encuentran relacionadas con materias diversas que en algún grado podrían afectar su posición legislativa. Por ejemplo Tronchet, el principal defensor del jus sanguinis en el Consejo de Estado, no puede ser ligado directamente a ninguna de estas teorías raciales. Era un hombre más bien conservador, que defendió como abogado a Luis XVI y que llevó muchas causas a fin de otorgar la ciudadanía francesa a sus clientes por ser descendientes de franceses antes de la Revolución. Aunque tenía un fuerte interés por la ciencia, esto no lo convierte, por sí mismo, en un partidario de las teorías raciales de su tiempo.

La cuestión es algo distinta cuando se analiza la obra de Sieyès. En su famoso ensayo Qu'est-ce que le Tiers état, el toma la posición de Boulainvilliers a fin de negar la validez del derecho de conquista como medio de justificar la pretensión de la nobleza de superioridad sobre el Tercer Estado ${ }^{69}$. El rechaza explícitamente que la conquista franca de las Galias otorgase a la aristrocracia un derecho a dominar a la población galo-romana. Por tanto, el Tercer Estado, los comunes en la nomenclatura del Antiguo Régimen, pueden reclamar sus derechos y demandar una nueva constitución. Aunque él mantiene y defiende una definición jurídica de nación ${ }^{70}$, donde el hecho de tener un Derecho común y un poder legislativo común serían sus características definitorias, él también parece mantener una visión naturalista de la nación, donde ésta pre-existiría a cualquier regla positiva y emanaría directamente del orden natural ${ }^{71}$. De hecho, al tener un orden jurídico y una representación legislativa distintas al Tercer Estado, la aristocracia -los francos- se auto-excluirían de la nación ${ }^{72}$. En este sentido, el Tercer Estado sería, en verdad, la única

\footnotetext{
${ }^{69}$ SIEYÈS (2002), p. 8. "Que si les aristocrates entreprennent, au prix même de cette liberté, dont ils se montreraient indignes, de retenir le peuple dans I'oppression, il osera demander à quel titre. Si I'on répond à titre de conquête, il faut en convenir, ce sera vouloir remonter un peu haut. Mais le tiers ne doit pas craindre de remonter dans les temps passés...".

70 "Qu'est-ce qu'une nation? Un corps d'associés vivant sous une loi commune et représentés par la même législature". SIEYÈs (2002), p. 5.

71 "La nation se forme par le seul droit naturel. Le gouvernement, au contraire, ne peut appartenir qu'au droit positif". SIEYÈs (2002), p. 54.

72 "Ainsi, ses droits civils en font déjà un peuple à part dans la grande nation. C'est véritablement imperium in imperio". SIEYÈs (2002), p. 5.
} 
nación en Francia, mientras que los descendientes de los francos no deberían ser contados entre ellos ${ }^{73}$.

Aunque Sieyés argumenta a favor de la igualdad, existe un elemento racial en su razonamiento que deriva directamente de una de las más tempranas teorías francesas que cientifica el racismo. Esto podría explicar su preferencia por el jus sanguinis en la discusión de la Constitución de 1799.

En el caso de Siméon, el principal antagonista del jus soli en el Tribunado, el vínculo es más fuerte. En su discurso en el Tribunado hay algunos guiños a la raza, como, por ejemplo, cuando defiende que al hijo de un francés que ha renunciado a su nacionalidad debiese inmediatamente serle concedida la ciudadanía francesa porque "tiene sangre francesa en sus venas"74. En cualquier caso, parece claro que él teme los efectos que los extranjeros podrían tener en la población francesa, puesto que considera que ${ }^{75}$ "nos exponemos seriamente a recibir a aquellos que, no teniendo patria, quieran enriquecerse con nuestros derechos, mientras nos infectan con sus vicios". Diecinueve años después, el mismo hombre critica amargamente la emancipación de los esclavos, diciendo que el árbol de la libertad puede producir frutos venenosos si no es adecuadamente cultivado ${ }^{76}$, puesto que su liberación debió haber sido una cuestión gradual, mientras que el haberles concedido la libertad inmediata fue un exceso, un simple fanatisme de la libertét7.

En la segunda sesión en que se discutió el problema del jus soli en el tribunado, en el 5 de Nivoso, el tribuno J.A. Perreau expuso una idea perturbadora

\footnotetext{
"Il faut entendre par le tiers état l'ensemble des citoyens qui appartiennent à l'ordre commun. Tout ce qui est privilégié par la loi, de quelque manière qu'il le soit, sort de l'ordre commun, fait exception à la loi commune, et par conséquent, n'appartient point au tiers état". SIEYÈs (2002), p. 6.

73 SieYÈs (2002), p. 8. "La nation, alors épurée, pourra se consoler, je pensé, d'être réduite à ne se plus croire composée que des descendants des gaulois et des romains. En vérité, si l'on tient à vouloir distinguer naissance et naissance, ne pourrait-on pas révéler à nos pauvres concitoyens que celle qu'on tire des gaulois et des romains vaut au moins autant que celle qui viendrait des sicambres, des welches et autres sauvages sortis des bois et des étangs de l'ancienne Germanie?".

74 "Son père a pu perdre sa qualité, mais il n'a pu alterer tout à fait le sang français qui coule dans les veines de son enfant", del discurso de Joseph-Jerome Siméon en Mavidal y LaURent (1864), p. 165.

75 "Nous serions exposés à recevoir parmi nous ceux qui, n'ayant pas de patrie, voudraient s'enrichir de nos droits et nous infecter de leurs vices", del discurso de Joseph-Jerome Siméon en MAVIDAL y LAURENT (1864), p. 166.

76 "...l'arbre de la liberté ne produit des poisons et la mort que par la faute de ceux qui le cultivent", SIMÉON (1824), p. 183.

77 SimÉOn (1824), p. 186.
} 
acerca de la nacionalidad ${ }^{78}$, donde una nación no sería otra cosa que la reunión de un número de familias que conforman una raza, la cual parece directamente relacionada con las ideas que el racismo científico se encuentra desarrollando. Los argumentos que Malherbe levantó en contra de sus proposiciones, alegando que se contravenía la tradición jurídica francesa y los principios de la Revolución, con citas de Montesquieu y Adam Smith, fueron insuficientes para revertir la marea.

\section{Conclusiones}

Aunque no podamos establecer un vínculo directo entre el racismo científico y los proponentes del jus sanguinis, el clima intelectual favoreció las distinciones raciales y le dio una suerte de bendición científica. A fines del siglo XVIII francés, los viejos prejuicios raciales se habían transformado en una teoría biológica completa que intentaba clasificar a la humanidad. En este contexto, el jus sanguinis, el derecho de sangre, tenía el ímpetu necesario para convertirse en el fundamento de la nacionalidad durante la era napoleónica y, más tarde, hacerse dominante en Europa. Durante la primera mitad del siglo XIX, debido a la influencia del Código Civil francés, el jus soli fue sistemáticamente suprimido de la mayor parte de los sistemas jurídicos europeos ${ }^{79}$ y reemplazado por el más moderno y "científico" jus sanguinis ${ }^{80}$.

Durante el siglo $\mathrm{XX}$, el jus soli ha retrocedido aún más, una vez que Inglaterra lo abandonó ${ }^{81}$. Aunque pueden encontrarse algunas excepciones, especialmente con la adopción de Alemania de algunos de los elementos del

78 "Dans chaque famille d'abord, el longtemps après, dans les premiers établissements de ces sociétés plus nombreuses, formées, sous le nom de nations, de la reunión des familles, ce n'était qu'à des souvenirs fixés par la continuité des affections et des usages que l'on confiait le soin de conserver les distinctions des individus et des races". En MAVIDAL y LaURENT (1864), p. 269.

${ }^{79}$ La ola de reformas se desarrolló en paralelo al proceso de codificación, aunque algunos países que no tenían aún Código Civil adoptaron el sistema a través de legislación miscelánea. El jus sanguinis fue adoptado en la mayor parte de los países europeos durante el siglo XIX: Austria (1811); Bélgica (1831); España (1837); Prusia (1842); Italia (1865); Rusia (1864); Holanda (1888); Noruega (1892) y Suecia (1894). WEIL (2001), p. 19.

${ }^{80}$ De hecho, cuando las reglas del jus sanguinis fueron reformadas en Francia en 1881, el jus soli era visto como una institución atrasada, reliquia del feudalismo europeo, extraño a las tradiciones francesas y a la ciencia moderna. BRUBAKER (1993), p. 11.

81 Desde la reforma de 1914, y especialmente con las leyes de 1981 y 1986, la legislación británica ha menoscabado consistentemente la aplicación del jus soli, hasta el punto que, lo que una vez constituyó una característica del derecho inglés es, hoy por hoy, más bien excepcional. Cesaranı (1996), p. I.1266. 
jus soli en su legislación ${ }^{82}$, otros países como Dinamarca (2004) lo abolieron por completo, salvo para los nacionales de otros países nórdicos ${ }^{83}$.

Con un fenómeno de inmigración creciente, estas reglas sólo incrementarán el número de apátridas que vivirán en Europa, algo esencialmente contrario al artículo 15(1) de la Declaración Universal de Derechos Humanos y al artículo $1^{\circ}$ de la Convención para Reducir los Casos de Apatridia de 1961.

Por otra parte, es casi absurdo exigir integración a personas a quienes el mismísimo sistema jurídico les dice que no pertenecen al país en que han nacido. Se los llama inmigrantes de segunda o tercera generación. Uno podría preguntarse, de dónde supuestamente han inmigrado, si es que han nacido en el territorio que los declara forasteros y puede que jamás hayan salido de él.

En Chile, a pesar de la fuerte influencia francesa que rodeó el proceso de emancipación, el jus soli ha formado parte de nuestra tradición jurídica desde el momento mismo de la independencia. Fue heredada directamente del Derecho castellano-indiano vigente a la hora de independizarnos ${ }^{84} \mathrm{y}$, afortunadamente, esta tradición ha sido mantenida de manera invariable en nuestra historia constitucional ${ }^{85}$. Al respecto, Andrés Bello reflexiona en su Tratado de Derecho Internacional ${ }^{86}$ :

"La sociedad en cuyo seno hemos recibido el ser, la sociedad que protegió nuestra infancia, parece tener más derecho que otra alguna sobre nosotros; derecho sancionado por aquel afecto al suelo natal, que es uno de los sentimientos más universales y más indelebles del corazón humano".

\footnotetext{
${ }^{82}$ VINK (2012), p. I.121.

${ }^{83}$ VINK (2012), p. I.222.

${ }^{84}$ Recordemos que las Siete Partidas ya contenían la regla:

P. 2,20,1 "Por mayor tovieron los sabios antiguos aquella naturaleza que los omes han con la tierra por nascer en ella".

Aunque la Novísima Recopilación se había apartado de la regla, esto fue convenientemente olvidado a comienzos del proceso independentista.

Nov. Rec. 1.3.19, y para un análisis en profundidad: Asso y Manuel (1806), p. 35; TApia García (1828), p. 7 y ESCRICHE (1875), p. 255.

${ }^{85}$ Constitución de 1822 , art. $4^{\circ}$. Son chilenos: $1^{\circ}$ Los nacidos en el territorio de Chile. $2^{\circ}$ Los hijos de chileno y de chilena, aunque hayan nacido fuera del Estado.

Constitución de 1823 , art. $6^{\circ}$. Son chilenos: $1^{\circ}$ Los nacidos en Chile. $2^{\circ}$ Los nacidos en otro país, si son hijos de padre o madre chilenos, y pasan a domiciliarse en Chile.

Constitución de 1828, art. $5^{\circ}$. Son chilenos naturales todos los nacidos en el territorio de la República. Constitución de 1833, art. $6^{\circ}$. Son chilenos: $1^{\circ}$ Los nacidos en el territorio de Chile.

${ }^{86}$ BelLo (1886), p. 108.
} 


\section{BiBLIOGRAFÍA CITADA}

Arangio-Ruiz, Vincezo (1914): Le genti e le città (Messina, Tipografia d'Angelo). Asso del Río, Jordán y MAnuel y Rodríguez, Miguel (1806): Instituciones del Derecho Civil de Castilla (Madrid, Tomás Albán), Tomo I.

AnÓnimo (año II de la República): Cathéchisme Français Republicaine, par un sans-culotte Français (Paris, Debarle).

Azonıs (1596): Ad singulas leges XII librorum Codicis Iustinianei (Ginebra, Jacobi

Stoer et Franc. Fabrj. Lugdunensis).

BALDO, Ubaldi (1577a): In I-XI Codicis Libros Commentaria (Venecia, Belilaquae). (1577b): Ad singulas leges XII librorum Codicis Iustinianei (Venecia, Belilaquae).

(1577c): In primam digesti veteris paterm commentaria (Venecia, Belilaquae).

BANG, Peter (1997): Antiquity between Primitivism and Modernism (Århus, Center for Cultural Research).

Bello, Andrés (1886): Derecho Internacional (Santiago, Pedro G. Ramírez).

BERDAH, Jean-François (2006): "Citizenship and National Identity in France from the French Revolution to the Present", en: Ellis, Steven G., Halfdanarson, Gudmundur y Isaacs, Ann Katherine (eds.), Citizenship in Historical Perspective (Pisa, Plus).

Berthencourt, Francisco (2013): Racisms, From the crusaders to the twentieth century (Princeton and Oxford, Princeton University Press, kindle edition).

Blackstone, William (1765): Commentaries on the Laws of England (Oxford, Clarendon Press).

Bonfante, Pietro (1963): Corso di diritto romano, Diritto di famiglia (Milano, Dott. A. Giuffrè Editore).

BRUBAKER, Rogers (1993): "De l'immigré au citoyen", en: Actes de la recherche en Sciences Sociales (99-1), pp. 3-25.

Cesarani, David (1996): "The Changing Character of Citizenship and Nationality in Britain", en: Cesarini, David y Fulbrook, Mary (Eds.), Citizenship, Nationality and Migration in Europe (London and New York, Routledge, Kindle).

Coin-Delisle, Jean-Baptiste-Cesar (1865): “Des français par naissance. Extrait de un nouveau commentaire, inédit, du titre de la Jouissance et de la privation des droits civils", en: Revue Critique de Législation et de Jurisprudence ( $\left.N^{\circ} 26\right)$, pp. 214-233. 
Conseil D'ÉtAt (1841): Discussion du Conseil d'État et du Tribunat sur le Code Civil: avant la rédaction définitive de chacune des Lois qui le composent (Paris, Firmin Didot frères).

Crawford, Michael (1970): "Money and Exchange in the Roman World", en: Journal of Roman Studies ( No 60), pp. 40-48.

Dalloz, Victor y Dalloz, Armand (1840): Jurisprudence générale du Royaume en matière civile, commerciale, criminelle et administrative et droit public (Paris, Dalloz).

De Boulainvilliers, Henri (1727): Histoire de l'Ancien Gouvernement de la France. Avec XIV letters histpriques fur les Parlemens ou Etats-Generaux (La Haye \& Amsterdam, s/E).

De Martino, Francesco (1953): "La gens, lo Stato e le classi in Roma antica", en: Studi in onore di Arangio-Ruiz (Napoli, Jovene), pp. 25-49.

Dumbraya, Costica (2014): Nationality, Citizenship and Ethno-Cultural belonging (Hampshire, Palgrave-Macmillan kindle).

ESCRICHE, Joaquín (1875): Diccionario Razonado de Legislación y Jurisprudencia (Madrid, Eduardo Cuesta), Vol. 4.

FINLey, Moses I. (1999): Ancient Economy (Berkeley, University of California Press).

Greene, Kevin (1990): The Archaeology of the Roman Economy (Berkeley, University of California Press).

Harris, William V. (2011): "A Revisionist View on Roman Money", en: Rome's Imperial Economy (Oxford, Oxford University Press, Kindle).

(2011): "Poverty and destitution in the Roman Empire", en: Rome's Imperial Economy (Oxford, Oxford University Press, Kindle).

HopkIns, Keith (2012): "Rome, Taxes, Rents and Trade", en: ScheIDEL, Walter y Von Reden, Sitta, The Ancient Economy (New York, Routledge), pp. 190-232.

KASER, Max (1960): "La famiglia romana arcaica", en: Conferenze romanistiche (Milano, Dott. A. Giuffré).

Kehoe, Dennis (2012): "Contract labor", en: Scheidel, Walter y Von Reden, Sitta, The Ancient Economy (New York, Routledge), pp. 114-131.

LeCLERC, Georges-Louis, Comte de Buffon (1834): Histoire naturelle de l'homme et de la femme (Paris, Armand Aubrée).

LinNaEus, Carl (1757): Systema naturae per tria regna naturae editio decima (Holmiae, s/E), Vol. 1. 
Lo Cascio, Elio (2000): "Mercato libero e comercio amministrato in età tardoantica", en: Mercanti e política nel mondo Antico (Roma, L'erma di Bretschneider), pp. 307-326.

Mavidal, J. y Laurent, E. (1864): Archives Parlementaires de 1787 à 1860 (Paris, Paul Dupont), Tomo III.

Marcone, Arnaldo (1997): Storia dell'agricoltura romana (Roma, Nuova Italia Scientifica).

Meikle, Scott (2012): "Modernism Economics and the Ancient Economy", en: Scheidel, Walter y Von Reden, Sitta, The Ancient Economy (New York, Routledge), pp. 233-250.

Mikkelsen, Jon M. (2013): Kant and the Concept of Race. Late eighteenth-century Writings (New York, Suny press, kindle).

Montesquieu, Charles-Louis (1772): L'esprit des lois (Londres, Nourse), Vol. I.

Morley, Neville (2006): "Social Structure and demography", en: Rosenstein, Nathan y Morstein-Marx, Robert (Eds.), A Companion to the Roman Republic (Oxford, Blackwell-Kindle Edition).

Ngaire Heuer, Jennifer (2007): The family and the nation: gender and citizenship in Revolutionary France, 1789-1830 (Ithaca, Cornell University Press).

PrICE, Polly J. (2013): "Natural Law and Birthright Citizenship in Calvin's Case", en: Yale Journal of Law and Humanities (Vol. 9, No 1), pp. 73-145.

Pothier, Robert Joseph (1846): Traité des personnes et des choses (Paris, Videdoq).

Pufendorf, Samuelis (1682=1927): De officio hominis et civis juxta legem naturalem libri duo (New York, Oxford University Press).

Pugliese, Giovanni (1985): "Aperçu historique de la famille romaine", en: Scritti giuridici scelti (Vol. 3) (Napoli, Jovene Editore).

SANTILLI, Aldo (1999): "Quaedam servitus: il colonus tra legislazione e pensiero giuridico", en: Societas-lus. Minuscula di allievi a Feliciano Serrao (Napoli: Jovene), pp. 275-292.

SIEYÈs, Emmanuel (2002): Qu'est-ce que le Tiers état (Paris, Boucher).

SimÉON, Joseph-Jérôme (1824): "Discours prononcé dans le comité secret des Cinq-Cents, à l'occasion du renvoi que les îles de France et de la Réunion (Bourbon) avaient fait des deux Commissaires du Gouvernement Burnet et Baco en I'an 5", en Joseph-JÉrôme Siméon, Choix de discours et opinions (Paris, Hacquart).

SiRKS, A. J. B. (1999): "Ne colonus inscio domino suum alienet peculium", en: Mélanges Fritz Strum (Vol. 1), pp. 419-430. 
(2008): "The colonate in Justinian's Reign", en: The Journal of Roman Studies (Vol. 98), pp. 120-143.

Tapia García, Eugenio (1828): Febrero Novísimo (Madrid, Mompié), Vol. 1.

TEMIN, Peter (2013): The roman market economy (Princeton: Princeton University Press).

VINK, Maarten Peter y De Groot, Gerard-René (2012): "Citizenship Attribution in Wetern Europe: International Framework and Domestic Trends", en: VINK, Maarten Peter, Migration and Citizenship Attribution. Politics and Policies in Western Europe (Oxon: Routledge).

VINNIUS, Arnoldus (1755): Institutionum Imperialium Commentarius v. 1 (Lugundi, Fratrum Detournes).

Vocl, Pascuale (1953): "Esame delle tesi del Bonfante sula Famiglia Romana Arcaica", en: Studi in onore di Arangio-Ruiz (Vol. 1).

Von Reden, Sitta (2012): "Money and Finance", en Scheidel, Walter (Ed.) The Cambridge Companion to the Roman Economy (Cambridge, Cambridge University Press), pp. 266-285.

WeIL, Patrick (2001): "Access to Citizenship: A comparison of Twenty-Five Nationality Laws", en: AleinIKOFf, Alexander y KLUSMEYER, Douglas, Citizenship Today: Global Perspectives and Practices (Washington, Carnegie Endowment for International Peace). (2008): How to be French. Nationality in the Making since 1789 (traducc. Porter, Catherine) (Durham and London, Duke University Press). 